\title{
Benchmarking electrical methods for rapid estimation of root biomass
}

\author{
François Postic ${ }^{1,2}$ and Claude Doussan ${ }^{2^{*}}$ (1)
}

\begin{abstract}
Background: To face climate change and subsequent rainfall instabilities, crop breeding strategies now include root traits phenotyping. Rapid estimation of root traits in controlled conditions can be achieved by using parallel electrical capacitance and its linear correlation with root dry mass. The aim of the present study was to improve robustness and efficiency of methods based on capacitance and other electrical variables, such as serial/parallel resistance, conductance, impedance or reactance. Using different electrode configurations and stem contact electrodes, we have measured the electrical impedance spectra of wheat plants grown in pots filled with three types of soil.
\end{abstract}

Results: For each configuration, parallel capacitance and other linearly independent electrical variables were computed and their quality as root dry mass estimator was evaluated by a'sensitivity score' that we derived from Pearson's correlation coefficient $r$ and linear regression parameters. The highest sensitivity score was obtained by parallel capacitance at an alternating current frequency of $116 \mathrm{~Hz}$ in three-terminal configuration. Using a clamp, instead of a needle, as a stem electrode did not significantly affect the capacitance measurements. Finally, in handheld LCR meter equivalent conditions, capacitance had the highest sensitivity score and determination coefficient $\left(r^{2}=0.52\right)$ at $10 \mathrm{kHz}$ frequency.

Conclusion: Our benchmarking of linear correlations between different electrical variables and root dry mass enables to determine more coherent practices for ensuring a sensitive and robust root dry mass estimation, including in handheld LCR meter conditions. This would enhance the value of electrical capacitance as a tool for screening crops in relation with root systems in breeding programs.

Keywords: Wheat, Triticum durum, Root mass, Electrical impedance spectrometry, Capacitance, Terminal configuration, Contact electrode

\section{Background}

Higher cereal yield are needed to feed a growing population in the near future [1]. However, partly as a consequence of climate change, yield of cereals tends to level off in different parts of the world as crops are facing more often sub-optimal conditions (water, nutrients, temperature) for growth [2]. The root system is a central actor in alleviating stress when inputs are suboptimal or limiting [3] and, in such conditions, water/nutrient capture is directly linked to root distribution and activity in soil in relation with the temporal pattern of resource

\footnotetext{
*Correspondence: claude.doussan@paca.inra.fr

2 UMR EMMAH, INRA, UAPV, Domaine Saint-Paul, Site Agroparc,

84914 Avignon, France

Full list of author information is available at the end of the article
}

availability. For example, depending on rainfall pattern, root proliferation in shallow soil layer may exhaust soil water too quickly before anthesis, detrimentally to yield, while deep rooting would be advantageous in capturing deep stored water at post-anthesis, and beneficial to yield [4-7]. Both modelling and field experiments showed that such a deep rooting could indeed increase or maintain grain yield for rainfed wheat $[8,9]$. Nevertheless, regardless of the root distribution pattern, increase/decrease in root density and biomass would be a factor influencing yield, depending on the environmental conditions $[6$, 7]. Besides, the early vigour and growth of root systems also plays a major role in drought tolerance, as shown for barley [10]. Whereas high-throughput phenotyping is developing extensively $[11,12]$, especially on aerial parts, 
root system traits' estimation is still time-consuming, expensive in terms of manpower and highly destructive [13]. In the context of crop selection based on root traits, including greenhouse and field selection stages [14], fast techniques for root systems characterization are relevant and needed [15]. Fast imaging techniques [16] and methods based on the root electrical properties could shorten greenhouse selection stages, but at the cost of limited pot size and varying measurement reliability, respectively.

A linear correlation between root mass and electrical capacitance has been empirically found [17] and, later, an equivalent electrical model has been proposed [18]. The capacitance measurement has been tested for different plants under greenhouse condition, for different potting conditions: soil, potting mix substrates, hydroponics, pots of different sizes [19-24]. It has been argued that the correlation between capacitance and root mass comes from allometric relationships in hydroponics [25, 26]. However, such electrical measurements were also successfully experimented these last years in the field for root length density estimation [27] and root trait selection in wheat [28]. In addition, 3D capacitance tomography has been used as a root distribution probe in laboratory [29].

Only few studies $[17,22]$ were aimed at improving the efficiency, practicability and sensitivity of root biomass estimation with electrical methods. The response of electrical methods applied to soil can be affected by environmental factors (soil water content, temperature, salinity) [30]. However, for soil-plant applications of electrical methods, the optimal experimental setup of measurement remains to be determined: current frequency and voltage, the number of terminals, the electrode type and the electrical variable used as a root mass estimator.

In this study, we propose to (1) evaluate the correlation between root dry mass (RDM, in g) and parallel capacitance over a frequency range of $0.5-20,000 \mathrm{~Hz},(2)$ measure the impact of electrode-stem contact on capacitance values, (3) measure the impact of terminal number on the coefficient of determination between root dry mass and capacitance, (4) compare different widely used electrical variables and (5) evaluate the accuracy of handheld equivalent LCR meter measurements.

\section{Theory}

\section{Electrical parameters and equivalent $\mathrm{RC}$ circuits}

In alternating current circuits, electrical impedance is an extension of the concept of resistance in Ohm's Law. Impedance is defined by two parameters, which are measured with an LCR meter: (1) the magnitude Z (equal to the ratio U/I, where $U$ and $I$ are the sinusoidal voltage and current amplitudes respectively), and (2) the phase angle $\theta$ (which expresses the phase shift between sinusoidal tension and current or equivalently the time difference between the maxima of sinusoidal current and tension). The variation of these two parameters with respect to frequency is the impedance spectrum. Impedance $\mathrm{Z}^{*}$ is a complex number that describes the effect of the circuit on both the magnitude and phase of the electrical signal. In complex notation, impedance can be decomposed in its real (in phase) and imaginary (out of phase) part as follow:

$$
Z^{*}=Z \times e^{j \theta}=Z \times \cos (\theta)+j \times Z \times \sin (\theta)
$$

where $j=\sqrt{-1}$. However, other electrical descriptions can also be used, assuming that the equivalent circuit of the investigated system is serial or parallel. In the case of serial circuits, classical simple variables would be either the resistance $\mathrm{R}$ (Eqs. 2, 3) and reactance X (Eqs. 2, 4) which are respectively the real and imaginary parts of impedance (both in $\Omega$ ), or expressed as elements of a serial RC circuit: the serial resistance $R_{s}$ (in $\Omega$, Eq. 6) and serial capacitance $C_{s}$ (in farads, Eq. 7) of. All these electrical variables can be expressed as functions of $Z$ and $\theta$, as follow:

$$
\begin{aligned}
& Z^{*}=R+j \times X \\
& R=Z \times \cos (\theta) \\
& X=Z \times \sin (\theta) \\
& Z=R_{s}+\frac{1}{j \times \omega \times C_{s}} \\
& R_{s}=Z \times \cos (\theta) \\
& C_{s}=\frac{-1}{\omega \times Z \times \sin (\theta)}
\end{aligned}
$$

$\omega=2 \pi f$ is the angular frequency, with $f$ frequency of injected current.

In the case of parallel circuits, classical variables would be the conductance G (Eq. 10) and susceptance B (Eq. 11), both in Siemens, which are the real and imaginary part of admittance $\mathrm{Y}^{*}$ (inverse of impedance, Eq. 8, in Siemens), respectively. The parallel resistance $R_{p}$ (in $\Omega$ ) and parallel capacitance $C_{p}$ (in farads) of the parallel $R C$ equivalent circuit are given by Eqs. 13 and 14 .

$$
\begin{aligned}
& Y^{*}=\frac{1}{Z^{*}}=G+j \times B \\
& Y=\frac{1}{Z e^{j \theta}} \\
& G=\frac{\cos (\theta)}{Z}
\end{aligned}
$$




$$
\begin{aligned}
& B=\frac{\sin (\theta)}{Z} \\
& \frac{1}{Z^{*}}=\frac{1}{R_{p}}+j \times \omega \times C_{p} \\
& R_{p}=\frac{Z}{\cos (\theta)} \\
& C_{p}=\frac{-\sin (\theta)}{\omega \times Z}
\end{aligned}
$$

Each of these interlinked variables could be tested for a link with plant roots. For simplifying the choice and number of electrical variables to be studied in relation with plant roots, we consider only those that are neither equal nor proportional to each other. Thus, we can discard $R$ which is equal to $R_{s}$, and $B$ which is proportional to $\mathrm{C}_{\mathrm{p}}$.

\section{Effect of injected current frequency}

A classic RC parallel circuit (i.e. a circuit with a constant capacitor $\mathrm{C}$ and a constant resistor $\mathrm{R}$ in parallel) displays a constant value of $C_{p}$ and $R_{p}$ over the whole spectrum (i.e. with any test signal frequency). Likewise, a $\mathrm{RC}$ serial circuit (i.e. a circuit with a constant capacitor $\mathrm{C}$ and a constant resistor $\mathrm{R}$ in series) displays a constant value of $\mathrm{C}_{\mathrm{s}}$ and $\mathrm{R}_{\mathrm{s}}$ over the whole spectrum. These simple circuits can be described by one or two electrical variables that are constant with respect to frequency.

However, in complex systems like biological entities, the electrical variable measured can show frequency dependence (e.g., measured $C_{p}$ varies with frequency). Such variations point to a more complex equivalent electrical circuit than a simple lumped RC circuit.

Furthermore, a non-linear behaviour of an electrical variable with frequency implies that comparison of two investigated systems is also frequency dependant. For example, if one uses an electrical parameter as an explanatory variable of the mass a plant root system, conclusions of comparative studies of two plants will depend on the frequency. A ratio of these two electrical parameters computed at a given frequency will differ from a ratio of these parameters computed at another frequency. As a consequence, measurements performed at different frequencies are not equivalent.

\section{Electrode configuration in impedance measurements}

Impedance measurements can be done with different electrode configurations, which are more or less sensitive to bias. Four-terminal (4T) sensing is a technique that eliminates the electrodes' contact impedance from measurement. This is achieved by separating pairs of current injection electrodes ( $\mathrm{C} 1$ and $\mathrm{C} 2)$ and voltage-measuring electrodes (P1 and P2). However, most measurements on plants are performed in a two-terminal (2T) configuration, where current and voltage-measuring electrodes are merged, leading to $\mathrm{C} 1-\mathrm{P} 1$ and $\mathrm{C} 2-\mathrm{P} 2$ electrode patterns. This configuration is sensitive to contact impedance. Finally, an intermediate configuration with three terminals $(3 \mathrm{~T})$ is made possible by merging a current electrode and a voltage-measuring electrode (e.g., merging $\mathrm{C} 1$ and $\mathrm{P} 1)$, analogous to ground resistance measurement.

\section{Methods}

\section{Soil and plant material}

We used three soil types of contrasting textures: a silt loam (20.9 \% sand, $53.3 \%$ silt and $25.8 \%$ clay), a loam (37.7 \% sand, $48.7 \%$ silt and $13.6 \%$ clay) and a sandy loam (60.4\% sand, $26.6 \%$ silt and $12.9 \%$ clay). Plastic pots $(12.5 \mathrm{~cm} \times 12.5 \mathrm{~cm} \times 22 \mathrm{~cm})$ were filled with $2.5 \mathrm{dm}^{3}$ of these air-dry soils, over a coarse sand and gravel layer for drainage. The field capacity of pots for the different potting substrates was estimated before sowing. Pots were watered with $500 \mathrm{~cm}^{3}$ of tap water. Three seeds of durum wheat (cv Isildur) were planted in each pot and the pots were transferred into a growth chamber maintained at $25{ }^{\circ} \mathrm{C}$. Twenty-four hours after sowing, $100 \mathrm{~cm}^{3}$ of tap water were added. After emergence, plants were brought to a greenhouse. The pots were thinned to one seedling per pot about 1 week after emergence. In the course of plant growth, pots were weighted regularly (each 2-3 days) and water added to reach the estimated field capacity. Electrical measurements in pots containing silt loam soil were performed $15,21,30,37$, and 45 days after sowing, with $4,2,2$, 2, 2 and 4 replicates, respectively. Measurements for pots containing loam and sandy loam substrates were performed 15, 30, 38 and 45 days after sowing, with 2 replicates for each sampling date. After electrical measurement completion, root systems were collected by carefully washing off the soil and collecting roots on $0.5 \mathrm{~mm}$ and $2 \mathrm{~mm}$ sieves. The roots were oven-dried at $65{ }^{\circ} \mathrm{C}$ for $24 \mathrm{~h}$ and their dry masses were precisely recorded on an electronic scale.

\section{Measurement of the electrical impedance spectrum}

Electrical impedance was measured with a SIP FUCHS III LCR-meter (Radic Research, Germany) at 26 logarithmically distributed, pre-programmed current frequencies, ranging from 0.5 to $20,000 \mathrm{~Hz}$, with $1 \mathrm{~V}$ terminal voltage. This device enables measurements with 2 terminals (2T), 3 terminals (3T) and 4 terminals (4T) configuration. The electrical variables delivered by the SIP FUCHS III are the magnitude of impedance $(Z)$ and the phase angle $(\theta)$. 


\section{Tests of different terminal configurations}

This first experiment involved 30 wheat plants. Those plants were successively measured in $2 \mathrm{~T}, 3 \mathrm{~T}$ and $4 \mathrm{~T}$ configurations. The electric circuit (Fig. 1) includes an alternating current source (electrodes $\mathrm{C} 1$ and $\mathrm{C} 2$ inserted into the plant and soil, respectively) and voltage was measured between electrodes P1 and P2. In each configuration, electrode $\mathrm{C} 1$, an alligator clamp with $15-\mathrm{mm}$ clamp width, was placed on the stem and maintained precisely $5 \mathrm{~cm}$ above the soil surface, and $10 \mathrm{~cm}$ long bronze rods (diameter $1 \mathrm{~mm}$ ) were used as soil terminal electrodes, inserted $3 \mathrm{~cm}$ deep into the potting soil. For $2 \mathrm{~T}$ experiments, electrodes C1-P1 (plant) as well as C2-P2 (soil) were merged. Soil terminal electrode $\mathrm{C} 2-\mathrm{P} 2$ was positioned $8 \mathrm{~cm}$ away from the stem base. For 3T experiments, plant electrodes $\mathrm{C} 1-\mathrm{P} 1$ were merged, and soil terminal electrodes $\mathrm{P} 2$ and $\mathrm{C} 2$ were positioned $4 \mathrm{~cm}$ and $8 \mathrm{~cm}$ away from the stem base, respectively. Finally, for 4T experiments, the plant terminal electrode P1 was placed few millimetres above the soil surface, and the soil terminal electrodes $\mathrm{P} 2$ and $\mathrm{C} 2$ were positioned $4 \mathrm{~cm}$ and $8 \mathrm{~cm}$ away from the stem base, respectively.

\section{Comparison between different electrode types}

In a second experiment, 30 wheat plants were subjected to plant-electrode contact comparison. When stems were

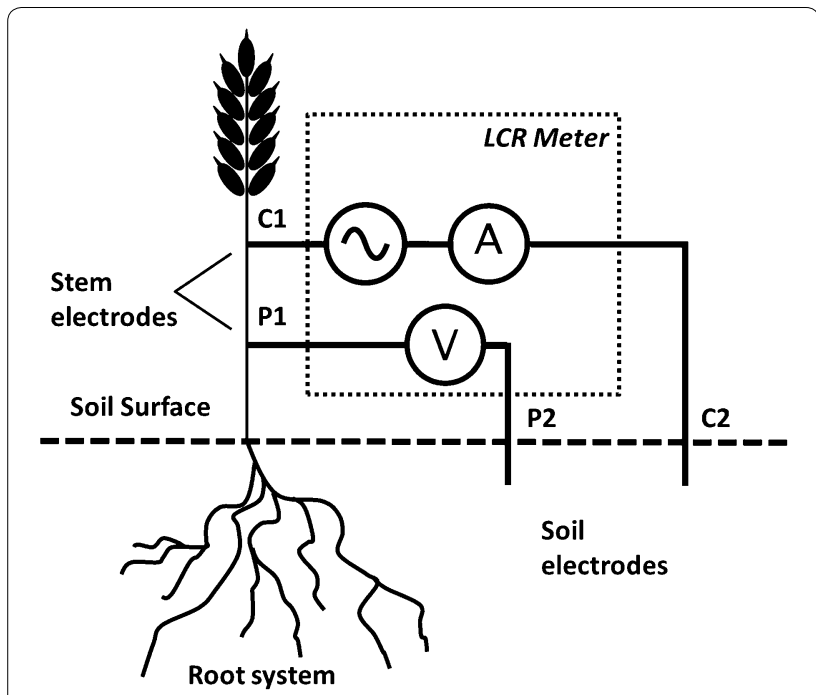

Fig. 1 Four-terminal (4T) sensing of plant-soil system. $P 1$ and $P 2$ are voltage-measuring electrodes. The LCR meter is simplified by an alternating current source, an ammeter A measuring current flowing between $C 1$ and $C 2$ electrodes and a voltmeter $V$ measuring voltage between $P 1$ and $P 2$ electrodes. Phase difference between measured current and measured voltage is also performed by the LCR meter. Three-terminal (3T) sensing used in this study is obtained by merging $C 1$ and $P 1$, and conventional two-terminal (2T) sensing is obtained by additionally merging $C 2$ and $P 2$ high enough, a stainless steel alligator clamp with $15 \mathrm{~mm}$ clamp width and a $0.5 \mathrm{~mm}$ diameter stainless steel needle were successively used as plant contact electrodes for measurements. From those data, the relative difference $\Delta C_{p}$ between $C_{c}$ and $C_{n}$, the parallel capacitances obtained with alligator clamp and needle, respectively, was calculated by $\left|C_{c}-C_{n}\right| / C_{c}$. To determine statistical significance of $\Delta C_{p}$, the distributions of capacitances $\left(C_{n}\right.$ and $C_{c}$ ) were compared using the Wilcoxon signed-rank test, with an $\alpha$ error of 0.01 .

\section{Comparison between different potting soils}

The third experiment involved 30 plants grown in pots filled with different soils (14 plants grown in silt loam, 8 in loam, 8 in sandy loam). The impacts of the three soil types on the coefficient of determination between root mass and electrical capacity have been compared.

\section{Electrical variables considered}

For each measurement, magnitude $(Z$, in $\Omega$ ) and phase angle $\left(\theta\right.$, in $\left.^{\circ}\right)$ of electrical impedance were obtained from SIP FUCHS III. From these basic complex parameters, different widely used electrical variable were computed [from Eqs. (4), (6), (7), (10), (13) and (14)]: Parallel capacitance $\left(C_{p}\right.$, in $\left.F\right)$, serial capacitance $\left(C_{s}\right.$, in $\left.F\right)$, parallel resistance $\left(R_{p}\right.$, in $\left.\Omega\right)$, serial resistance $\left(R_{s}\right.$, in $\left.\Omega\right)$, conductance $(G$, in $S$ ) and reactance (X, in $\Omega$ ).

\section{Quality ranking of root mass predictors}

A linear correlation $(y=a R D M+b)$ between root dry mass (RDM) and each electrical variable $(y)$ has been calculated for each of the 26 measurement frequencies. Computations of linear model parameters (slope $a$ and $y$-intercept $b$ ) and coefficient of determination $r^{2}$ were performed using Matlab ('nlinfit' routine). The maximum determination coefficient between an electrical variable and root dry mass is denoted as $r_{\operatorname{mat}}^{2}$ (dimensionless) and the corresponding frequency, $f_{\max }(\mathrm{Hz})$, is called 'maximum determination frequency'. Ideal sensors are designed to deliver a response proportional to the measurand [31]. This linear behaviour between input and output ensures: (1) a constant sensitivity free of saturation effects, and (2) a reduced static error, i.e. linearity prevents additional error issued from a conversion of non-linear input signal to linear output. With a constant sensitivity in the measurement range, a linear response will best allow the comparison between two measurements.

However, the determination coefficient $r^{2}$ is not a sufficient criterion for rating the efficiency of a root mass predictor. Another key criterion is the sensitivity to a variation of the estimated root mass. In other words, the ratio between two different root masses should ideally 
equal the ratio of two measurements of an electrical variable. For linear correlation, it is equivalent to a negligible value of the ratio between interception and slope for a characteristic mass of root.

For two given root masses $m_{1}$ and $m_{2}$, two measurements of an electrical variable are obtained $\left(y_{1}\right.$ and $\left.y_{2}\right)$, thus:

$$
\frac{y_{1}}{y_{2}}=\frac{a \times m_{1}+b}{a \times m_{2}+b}
$$

For a given characteristic root mass, i.e. the order of magnitude of the average root mass measured, we can state:

$m_{1}=\alpha \times m_{0}$ and $m_{2}=\beta \times m_{0}$ with $\alpha \approx 1$ and $\beta \approx 1$.

Thus Eq. (15) becomes:

$$
\begin{aligned}
& \frac{y_{1}}{y_{2}}=\frac{\alpha+\frac{b}{a \times m_{0}}}{\beta+\frac{b}{a \times m_{0}}} \\
& \text { If }\left|\frac{b}{a \times m_{0}}\right|<<1
\end{aligned}
$$

Equation (16) becomes: $\frac{y_{1}}{y_{2}}=\frac{\alpha}{\beta}=\frac{m_{1}}{m_{2}}$, which is the true ratio between the root masses. Thus, as shown in Eq. (17) when this ratio become close to 1 or is higher, the sensitivity of electrical variable is poor, and it makes the electrical variable unreliable for comparison of root masses.

In order to rank the electrical variables tested as predictors of root dry mass, we introduced a 'sensitivity score' $s$, calculated as follows:

$$
s=\max \left(r_{\max }^{2} \times\left(1-\left|\frac{b}{a \times m_{0}}\right|\right) ; 0\right)
$$

where $m_{0}$ (in g) is a characteristic mass of dry roots, in our case $m_{0}=1 \mathrm{~g}$. The sensitivity score represents the accuracy of the comparison between measurements obtained from 2 plants, with the same order of magnitude of root dry mass $\left(m_{0}\right)$. A maximum score $(s=1)$ means that the ratio between two measurements is equal to the ratio between two plants root mass. A minimum score $(s=0)$ means that only very large variations of root mass would be reliably estimated.

\section{Literature data}

Data that we could retrieve from prior experiments on the quantification of plant root biomass using electrical capacitance were compiled [18, 19, 22-25, 32]. Most of these experiments used $C_{p}$ measured in a $2 \mathrm{~T}$ configuration at $1 \mathrm{kHz}$ for root biomass estimation. The growth media, the measured characteristic biomass of wet or dry roots, the parameters linear regression found between root biomass and $\mathrm{C}_{\mathrm{p}}$ and the coefficient of determination were extracted in order to computed their respective $y$-intercept:slope ratio (Eq. 17) and their 'sensitivity score' $s$ (Eq. 18). The measured characteristic biomass of roots was roughly the median of root biomass measured in each experiment.

\section{Results}

\section{Root mass}

The harvested plants presented a root mass ranging from 0.02 to $0.72 \mathrm{~g}$, with a mean value of $0.2 \mathrm{~g}$ and a standard deviation of $0.19 \mathrm{~g}$. This reflects the fact that plants were harvested at different times and that they were relatively young (Additional file 1).

\section{Frequency dependence of the parallel capacitance: root dry mass correlation}

Determination coefficients from linear correlations between root dry mass and parallel capacitance are plotted in Fig. 2 as a function of frequency. The correlation between $\mathrm{C}_{\mathrm{p}}$ and RDM is frequency-dependant. The same pattern occurs in $2 \mathrm{~T}$ and $4 \mathrm{~T}$ configurations (Additional file 2: Figure S1, Additional file 3: Figure S2). On average for the 3 soil types, the maximum determination value $r_{\max }^{2}(p<0.01)$ between root dry mass (RDM) and $\mathrm{C}_{\mathrm{p}}$ equals 0.787 , and occurs at a maximum determination frequency $f_{\max }$ of $116 \mathrm{~Hz}$. In this configuration, the RDM (in g) relation with $\mathrm{C}_{\mathrm{p}}(\mathrm{in} \mathrm{nF})$ is:

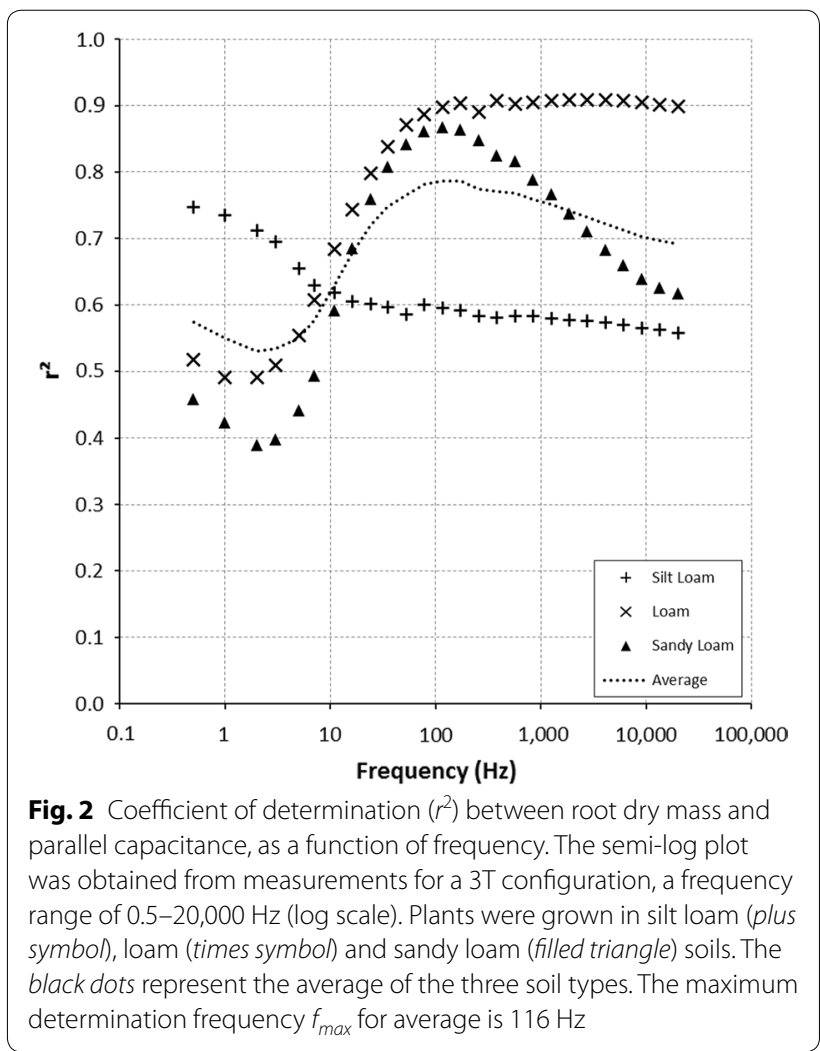




$$
C_{p}=4.2 \times R D M+0.37
$$

The magnitude of $r^{2}$ at $f_{\text {max }}$ depends on the soil. Thus, at $f_{\text {max }}=116 \mathrm{~Hz}$, the determination coefficient from the linear correlation between biomass and $\mathrm{C}_{\mathrm{p}}$ in a loam soil reaches high value $\left(r^{2}=0.898\right)$, while a silty loam soil has a lower maximum $r^{2}$ value of 0.595 . In addition, each soil type displays different $f_{\max }$ value, in all terminal configurations.

\section{Effect of plant electrode type: clamp versus needle electrode on average for the three soil types}

The mean relative differences in parallel capacitance $\Delta C_{p}$, between needle measurements and clamp measurements, are shown in Fig. 3. As a general trend, the relative difference $\Delta C_{p}$ tends to increase with the test signal frequency. The relative difference is $<20 \%$ over the range of $0.5-100 \mathrm{~Hz}$ and is $\sim 6 \%$ for low frequency $2 \mathrm{~T}$ measurements. However, relative differences in $4 \mathrm{~T}$ measurements exceed $20 \%$ for frequencies over $100 \mathrm{~Hz}$ and peaks to $180 \%$ at $1250 \mathrm{~Hz}$. Nevertheless, 2T and 3T configurations exhibit a relative difference maximum of $50 \%$, down to $6 \%$, especially for 3T measurements in the frequency range of $0.5-172 \mathrm{~Hz}$. Additionally, in $2 \mathrm{~T}$ configuration, the relative difference was not statistically significant $(p$ value $>0.01$ ) in the frequency range of $0.5-13,458 \mathrm{~Hz}$.

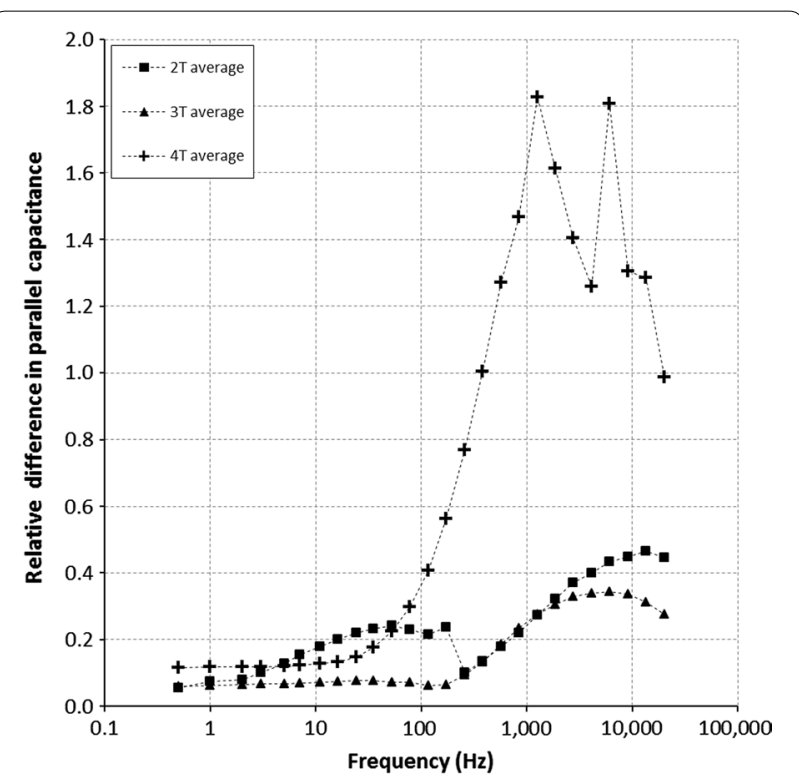

Fig. 3 Impact of the stem contact electrode on the measured electrical capacitance of the plant-soil system. Plot of the mean relative difference between the parallel capacitance measured with a clamp and that measured with a needle, as a function of frequency, in $2 T$ (filled square), $3 \mathrm{~T}$ (filled triangle) and $4 \mathrm{~T}$ (plus symbol) configurations. Differences are $<6 \%$ for frequencies $<200 \mathrm{~Hz}$ in $3 \mathrm{~T}$ configuration
The same occurred for 3T and 4T configurations, but in the narrower frequency range of $0.5-381 \mathrm{~Hz}$.

\section{Performance of electrical variables for root dry mass prediction}

Table 1 shows, for all the electric variables studied the sensitivity scores, maximum of coefficient of determination from the linear correlation with root dry mass and maximum determination frequency $f_{\max }$ averaged over the three soil types investigated. An exhaustive list of the regression parameters used for the $s$ score calculations are given in Additional file 1 and illustrations of a good, moderate and low score are provided in Additional files 4, 5 and 6 respectively. Parallel capacitance $C_{p}$ reaches a maximum $r^{2}$ value with RDM in 3T configuration $\left(r_{m \overline{a x}}^{2} 0.787\right)$, while it exhibits a slightly lower maximum $r^{2}$ value $\left(r_{m \overline{\overline{a x}}}^{2} 0.771\right)$ in $2 \mathrm{~T}$ configuration. In $3 \mathrm{~T}$ configuration, all electrical variables display a $r_{\max }^{2}$ lose to 0.7 , except for the phase angle $\left(r_{m}^{2} \overline{\overline{a x}} 0.331\right)$. However, $f_{\max }$ differs for all variables, ranging from 3 to $20,000 \mathrm{~Hz}$ in $2 \mathrm{~T}, 116$ to $20,000 \mathrm{~Hz}$ in $3 \mathrm{~T}$ and 0.5 to $20,000 \mathrm{~Hz}$ in $4 \mathrm{~T}$ configuration. Regarding sensitivity scores, the parallel capacitance $\mathrm{C}_{\mathrm{p}}$ displays the best score in 3T configuration $(s=0.717)$, followed by serial capacitance $C_{\mathrm{s}}(s=0.688)$ and conductance $\mathrm{G}(s=0.679)$. For all variables except phase angle $\theta$, sensitivity scores were higher in $3 \mathrm{~T}$ than in $2 \mathrm{~T}$ and $4 \mathrm{~T}$ configurations. In general, our sensitivity score changes the ranking of electrical variables by their determination coefficient with root dry mass. In all terminal configurations, $\mathrm{C}_{\mathrm{p}}, \mathrm{C}_{\mathrm{s}}$ and $\mathrm{G}$ exhibit the best sensitivity scores, especially in $4 \mathrm{~T}$ measurement where $R_{p}, R_{s}, Z$ and $X$ scores are null, meaning that these variables are not reliable for root mass estimation.

\section{Performance of terminal configurations for root dry mass estimation}

The number of terminals is generally related to the coefficient of determination from linear correlations between electrical variables and RDM (Table 1). The 3T measurements exhibit the best $r^{2}$ values, while $2 \mathrm{~T}$ measurements have slightly lower, yet close, $r^{2}$ values. Four-terminal configuration shows the worst determination of RDM, with $r^{2}<0.5$. Parallel capacitance $\left(C_{\mathrm{p}}\right), \mathrm{C}_{\mathrm{s}}$ and $\mathrm{G}$ maximum determination frequencies increase with the number of terminals. The $2 \mathrm{~T}$ (see Additional file 2) and $3 \mathrm{~T}$ measurements exhibit similar $y$-intercept/slope ratios of the linear regression, but lower than that of $4 \mathrm{~T}$ measurements (see Additional file 3). This means that this latter configuration is less sensitive to the root biomass variations. Most of experiments relating root biomass and electrical capacitance in the literature were performed with handheld LCR meters in $2 \mathrm{~T}$ configuration. Most of the time, the test signal frequency used is $1000 \mathrm{~Hz}$, but 100 and 10,000 Hz 
Table 1 Signal frequencies leading to the highest scores for electrical variable depending on the chosen terminal configuration

\begin{tabular}{|c|c|c|c|c|}
\hline $\begin{array}{l}\text { Electrical vari- } \\
\text { able }\end{array}$ & $\begin{array}{l}\text { Terminal con- } \\
\text { figuration }\end{array}$ & $\begin{array}{l}\text { Sensitivity } \\
\text { score }\end{array}$ & $r_{\max }^{2}$ & $f_{\text {max }}(\mathrm{Hz})$ \\
\hline \multirow[t]{3}{*}{$C_{p}$} & $2 T$ & 0.71 & $0.771^{* * *}$ & 78 \\
\hline & $3 T$ & 0.72 & $0.787^{* * *}$ & 116 \\
\hline & $4 \mathrm{~T}$ & 0.45 & 0.560 & 566 \\
\hline \multirow[t]{3}{*}{$C_{s}$} & $2 \mathrm{~T}$ & 0.48 & $0.520^{* *}$ & 3 \\
\hline & $3 T$ & 0.69 & $0.754^{* * *}$ & 6094 \\
\hline & $4 \mathrm{~T}$ & 0.28 & 0.353 & 20,000 \\
\hline \multirow[t]{3}{*}{$R_{p}$} & $2 T$ & 0.44 & $0.657^{* * *}$ & 78 \\
\hline & $3 T$ & 0.53 & $0.797^{* * *}$ & 841 \\
\hline & $4 \mathrm{~T}$ & 0.00 & 0.377 & 9056 \\
\hline \multirow[t]{3}{*}{$R_{s}$} & $2 \mathrm{~T}$ & 0.45 & $0.642^{* *}$ & 9056 \\
\hline & $3 T$ & 0.54 & $0.791^{* * *}$ & 4101 \\
\hline & $4 \mathrm{~T}$ & 0.00 & 0.348 & 20,000 \\
\hline \multirow[t]{3}{*}{ G } & $2 T$ & 0.52 & $0.585^{* *}$ & 78 \\
\hline & $3 T$ & 0.68 & $0.751^{* * *}$ & 4101 \\
\hline & $4 \mathrm{~T}$ & 0.31 & 0.398 & 20,000 \\
\hline \multirow[t]{3}{*}{ Z } & $2 T$ & 0.43 & $0.645^{* * *}$ & 78 \\
\hline & $3 T$ & 0.53 & $0.795^{* * *}$ & 1857 \\
\hline & $4 \mathrm{~T}$ & 0.00 & 0.357 & 1,3458 \\
\hline \multirow[t]{3}{*}{$x$} & $2 T$ & 0.46 & $0.653^{* *}$ & 20,000 \\
\hline & $3 T$ & 0.55 & $0.794^{* * *}$ & 6094 \\
\hline & $4 \mathrm{~T}$ & 0.00 & 0.330 & 20,000 \\
\hline \multirow[t]{3}{*}{$\theta$} & $2 T$ & 0.05 & 0.331 & 20,000 \\
\hline & $3 T$ & 0.10 & $0.752^{* * *}$ & 20,000 \\
\hline & $4 \mathrm{~T}$ & 0.26 & 0.374 & 0.5 \\
\hline
\end{tabular}

The sensitivity scores, the maximum of the coefficient of determination with root dry mass $\left(r_{\text {max }}^{2}\right)$ and the maximum determination frequency $\left(f_{\max }\right.$, in $\left.\mathrm{Hz}\right)$, for parallel capacitance $\left(C_{p}\right)$, serial capacitance $\left(C_{s}\right)$, parallel resistance $\left(R_{p}\right)$, serial resistance $\left(R_{s}\right)$, conductance magnitude $(G)$, impedance magnitude $(Z)$, reactance $(X)$ and phase angle $(\theta)$, in $2 \mathrm{~T}, 3 \mathrm{~T}$ and $4 \mathrm{~T}$ configurations averaged for the three soil types studied

*** Linear regression is significant at the 0.01 level

** Linear regression is significant at the 0.05 level

frequencies are also available on LCR meters. Table 2 shows the results of our experiments close to these measurement conditions: frequencies considered are 116, 1250 and $13,458 \mathrm{~Hz}$ with $2 \mathrm{~T}$ configuration.

Among electrical variables, parallel capacitance displays the highest sensitivity score $(s=0.50)$ of all variables at $13,458 \mathrm{~Hz}$. Considering only determination coefficients, and thus ignoring the sensitivity, reactance reaches the highest coefficient of determination $\left(r^{2}=0.649\right)$, this makes it the best choice. Interestingly, at $1250 \mathrm{~Hz}$ frequency, parallel capacitance reaches the highest sensitivity over all other variables. However its sensitivity score at $1250 \mathrm{~Hz}$ $(s=0.46)$ is lower than at $13,458 \mathrm{~Hz}(s=0.50)$. This would
Table 2 Sensitivity scores for each electrical variable in conditions similar to the widely used LCR meters

\begin{tabular}{|c|c|c|c|}
\hline Electrical variable & Frequency $(\mathrm{Hz})$ & Sensitivity score & $r^{2}$ \\
\hline \multirow[t]{3}{*}{$C_{p}$} & 116 & 0.49 & 0.542 \\
\hline & 1250 & 0.46 & 0.524 \\
\hline & 13,458 & 0.50 & 0.605 \\
\hline \multirow[t]{3}{*}{$C_{s}$} & 116 & 0.10 & 0.119 \\
\hline & 1250 & 0.29 & 0.331 \\
\hline & 13,458 & 0.38 & 0.436 \\
\hline \multirow[t]{3}{*}{$R_{p}$} & 116 & 0.40 & $0.584^{* *}$ \\
\hline & 1250 & 0.45 & $0.635^{* *}$ \\
\hline & 13,458 & 0.38 & $0.599^{* *}$ \\
\hline \multirow[t]{3}{*}{$R_{s}$} & 116 & 0.39 & $0.563^{* *}$ \\
\hline & 1250 & 0.44 & $0.615^{* *}$ \\
\hline & 13,458 & 0.44 & $0.639^{* *}$ \\
\hline \multirow[t]{3}{*}{ G } & 116 & 0.28 & 0.317 \\
\hline & 1250 & 0.35 & 0.394 \\
\hline & 13,458 & 0.45 & 0.502 \\
\hline \multirow[t]{3}{*}{ Z } & 116 & 0.39 & $0.574^{* *}$ \\
\hline & 1250 & 0.44 & $0.628^{* *}$ \\
\hline & 13,458 & 0.41 & $0.622^{* *}$ \\
\hline \multirow[t]{3}{*}{$x$} & 116 & 0.18 & 0.281 \\
\hline & 1250 & 0.42 & $0.595^{* *}$ \\
\hline & 13,458 & 0.46 & $0.650^{* *}$ \\
\hline \multirow[t]{3}{*}{$\Theta$} & 116 & 0.00 & 0.197 \\
\hline & 1250 & 0.00 & 0.214 \\
\hline & 13,458 & 0.03 & 0.267 \\
\hline
\end{tabular}

The sensitivity scores, coefficients of determination with root dry mass $\left(r^{2}\right)$, for each electrical variable in LCR meter conditions (test signal frequencies of 116,1250 and $13,458 \mathrm{~Hz}$, in $2 \mathrm{~T}$ configuration). The highest sensitivity score is obtained by parallel capacitance $\left(C_{p}\right)$ at $13,458 \mathrm{~Hz}$

*** Linear regression is significant at the 0.01 level

** Linear regression is significant at the 0.05 level

make $\mathrm{C}_{\mathrm{p}}$ measured at $13,458 \mathrm{~Hz}$, the best choice in terms of sensitivity and precision for root biomass estimation in $2 \mathrm{~T}$ configuration with handheld meters.

\section{Effect of the growth media on root electrical relationship: data from literature}

The sensitivity scores $s$ obtained by previous studies are shown in Table 3 and the determination coefficients $r^{2}$ obtained in different growth media (including soils, potting substrates, hydroponics) are shown Fig. 4. The highest $s$ and $r^{2}$ values are obtained in hydroponics $(s=0.99$ $0.64, r^{2}=0.99-0.67$ ), whereas artificial potting substrate (vermiculite, compost, sheep manure) had the lowest $s$ values $(s=0.30-0.00)$. The experiments involving natural soils exhibited intermediate $s$ values $(s=0.51-0.36)$, and strong $r^{2}$ values $\left(r^{2}=0.82-0.50\right)$. Few data involve clay soils, while most studies focused on sandy to loamy soils. 
Table 3 Compilation of linear regression parameters between parallel capacitance and root mass, and corresponding sensitivity scores from literature data

\begin{tabular}{|c|c|c|c|c|c|c|c|}
\hline Publication & Species & $\begin{array}{l}\text { Characteristic } \\
\text { root mass } m_{0}(g)\end{array}$ & $b /\left(a \times m_{0}\right)$ & $r^{2}$ & $s$ & Growth media & Comments \\
\hline \multirow[t]{6}{*}{ Chloupek [17] } & Zeamays & - & - & 0.728 & - & Sand & Dried \\
\hline & Allium cepa & - & - & 0.545 & - & Sand & Dried \\
\hline & Helianthus annuus & - & - & 0.897 & - & Sand & Dried \\
\hline & Avena sativa & - & - & 0.464 & - & Clay soil & Dried \\
\hline & Helianthus annuus & - & - & 0.432 & - & Clay soil & Dried \\
\hline & Brassica napus & - & - & 0.081 & - & - & Fresh \\
\hline \multirow[t]{2}{*}{ Chloupek [37] } & Daucus carota & - & - & 0.514 & - & Loam (field) & Fresh \\
\hline & Helianthus annuus & - & - & 0.566 & - & Sand & Fresh \\
\hline \multirow[t]{2}{*}{ Kendall et al. [32] } & Medicago sativa & 0.2 & 0.03 & 0.50 & 0.48 & Silt loam (field) & Dried \\
\hline & Trifolium Pratense & - & - & 0.67 & - & Hydroponics & Dried \\
\hline Dalton [18] & Solanum lycopersicum Mill. & 2 & 0.17 & 0.77 & 0.57 & Hydroponics & Dried \\
\hline \multirow[t]{2}{*}{ van Beem et al. [24] } & Zea mays L. & 100 & 0.17 & 0.53 & 0.44 & Loam (field) & Fresh \\
\hline & & 5 & 1.33 & 0.73 & 0.00 & Vermiculite & Fresh \\
\hline \multirow{2}{*}{$\begin{array}{l}\text { Ozier-Lafontaine and } \\
\text { Bajazet [23] }\end{array}$} & Solanum lycopersicum Mill. & 1 & 0.55 & 0.82 & 0.36 & Clay loam & Dried \\
\hline & Solanum lycopersicum Mill. & 1 & 0 & 0.99 & 0.99 & Hydroponics & Dried \\
\hline Aulen and Sipley [19] & Herbaceous species & 0.1 & 0 & 0.30 & 0.3 & Compost & Dried \\
\hline Dietrich et al. [25] & Triticum aestivum L. & 1 & 0.32 & 0.75 & 0.51 & Sand & Dried \\
\hline Ellis et al. [36] & Vicia faba L. & 10 & 0.48 & 0.31 & 0.16 & Sheep manure & Fresh \\
\hline Present study & Triticum turgidum L. ssp. durum & 1 & 0.09 & 0.787 & 0.72 & $\begin{array}{l}\text { Silt loam, loam, } \\
\text { sandy loam }\end{array}$ & Dried \\
\hline
\end{tabular}

\section{Discussion}

This work shows that the accuracy of electrical variables used for predicting biomass is frequency-dependent. The best estimates were obtained within a specific frequency range, using parallel capacitance as a proxy for biomass estimator. Our experiments, like others from the literature, involve plant and soil electrical probing. In other words, soil electrical response is also measured and can interfere with plant response. Thus regarding the parallel capacitance, the frequency range where the $r^{2}$ values are low, may correspond to the frequency range where the soil electrical response is stronger than the plant electrical response. Soil texture induces variations of this frequency range (Fig. 2), supporting that the full electrical response spectrum is a combination of soil and plant responses. Furthermore, the frequency dependence of parallel capacitance implies that plant system cannot be simplified to a simple RC parallel circuit. In such circuit, $C_{p}$ is constant over the whole frequency range. This implies that an electrical equivalent of plant-soil system is composed of several parallel RC circuits, exhibiting several relaxation times. This frequency dependence has also been reported on other plants than wheat, such as tomatoes [23].

Among factors affecting the electrical response of this soil-plant method, root type or soil conditions have been shown to interact with the signal. Indeed, woody and non-woody roots may respond differently [33, 34] due to a difference in their inner root structure. Heterogeneity of the growing medium alters the electrical relation: nonhomogeneous substrate (e.g. manure or compost) display the lowest coefficients of determination [19, 22, Fig. 4] and in a lesser extent, results may vary from hydroponics to real soils (Fig. 4), and from pot to field experiments [24]. Soil water content appears as the most influential environmental factor $[25,27,32]$ and, consequently, as a major constituent in the reliability and accuracy of measurements when it varies. The soil water content effect was minimised in our study, since pots were adjusted at field capacity before measurements. However, this factor will undeniably add noise to the electrical relation if it is variable, particularly in the field [35].

In the range of low frequencies $(<200 \mathrm{~Hz})$, for plants like wheat, needle measurements only slightly differ from clamp measurements. This implies that the electrical current path is not mastered by the different contact types of these electrodes. Even if xylem is the best carrier of electrical current, it appears that stem impedance is small over the width of a clamp. Its additive effect on measured impedance is negligible in comparison with whole plant impedance. Furthermore, clamps are less destructive and more practicable than needles and could be preferred for 


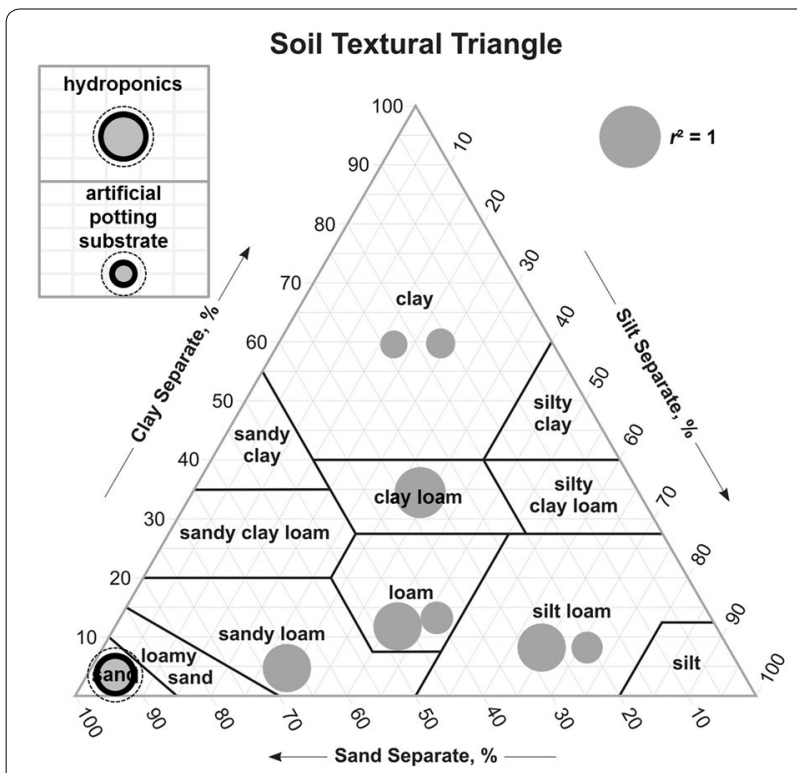

Fig. 4 Growth media used in root biomass estimation found in related literature and in our study. The size of the circles is proportional to the coefficient of determination $r^{2}$ found in each study. When more than two studies involved the same growth media, the mean (in black ring), the minimum (in grey circle) and the maximum (dashed circle) of coefficient of determination $r^{2}$ were plotted

root capacitance measurements. At higher frequencies, needle and clamp measurements can exhibit discrepancies. This is particularly true for the $4 \mathrm{~T}$ configuration, for which the relative difference between electrode types peaks at $180 \%$. 4T configuration is generally known for being more reliable. It eliminates contact impedance and enables precise measurements of impedance. Thus, the higher differences between needle and clamp measurements found with $4 \mathrm{~T}$, compared with $2 \mathrm{~T}$ and $3 \mathrm{~T}$ configurations in our experiment, could seem counter-intuitive. These larger differences found in $4 \mathrm{~T}$ may have various causes.

Firstly, needle electrodes, implanted trough the stem, are more invasive than clamp electrodes. Perturbation of the flow in the xylem can occur and modify the displacement of the electric charges between electrodes, creating a parasitic effect in the measured medium. This parasitic effect on the charge carrying medium is supported by the lower coefficients of determination with root dry mass found in $4 \mathrm{~T}$ configuration.

Secondly, it has been shown that measured capacitance is very sensitive to electrode position on the stem $[18,36]$, in particular for electrode located close to the base of the stem. Our 4T configuration measurements involved electrode contact very close to the base of the stem (few $\mathrm{mm}$ ). Thus a small deviation on the position of the electrode located at the base of the stem could imply a large difference in the measured capacitance.
In our experiments, $2 \mathrm{~T}$ and $3 \mathrm{~T}$ configurations are less sensitive to the stem electrode position. This electrode was located much higher $(5 \mathrm{~cm})$, and thus less sensible to a deviation on its position. In consequence, differences found between needle and clamp measurements in $2 \mathrm{~T}$ and 3T configurations are much lower.

Depending on the type of terminal configuration, the measurements may be biased in different ways. For example, in $2 \mathrm{~T}$ configuration, measurements could biased by wire and contact impedance, while in $4 \mathrm{~T}$ configuration, a more representative impedance, eliminating contacts and wire effects, of the device under test would be measured. The 3T configuration is an intermediate configuration, where only contact impedance of the plant electrode is involved. The lower correlations with root dry mass in $4 \mathrm{~T}$ configuration than in $2 \mathrm{~T}$ and $3 \mathrm{~T}$ are probably due to plant electrode issues.

Finally, it appears that classical handheld LCR meter measurements could be revised in terms of frequency and electrical variable used. In the terminal configuration used by this kind of device, i.e. 2T configuration, $\mathrm{C}_{\mathrm{p}}$ obtained the best sensitivity score at around $10 \mathrm{kHz}$. However, in these handheld LCR equivalent configurations, sensitivity scores obtained were significantly lower than sensitivity scores obtained with the optimal configuration, i.e. using a $3 \mathrm{~T}$ configuration at $116 \mathrm{~Hz}$.

As shown Table 3, hydroponics shows the best conditions for root biomass estimation using electrical $C_{p}$. This growth media exhibits an optimal contact with roots as well as homogeneity. In real soils, the root-medium contact is not controlled, the heterogeneity is greatly increased. This results in less precise root biomass estimations, but the electrical-root biomass relationship is still effective. This work enhances root biomass estimations under more representative conditions, by using various real soils instead of hydroponics, providing framework for agronomical relevant root studies.

\section{Conclusions}

In this study, we found that the estimation of wheat root biomass through electrical measurements would be more accurate when performed in 3T configuration with a $116 \mathrm{~Hz}$ frequency and using parallel capacitance as the electrical variable. With this measurement setting, low differences $(6.7 \%)$ were found when using clamp or needle as plant contact electrode. This result means that reliable measurements can be achieved by using clamps, which are more practicable and less destructive than needles trough stem. We also found that a handheld LCR meter could result in better measurements when used at $10,000 \mathrm{~Hz}$ and measuring parallel capacitance, even though reactance obtained better determination coefficients from linear correlation with root dry mass. These 
methodological optimizations strengthen the robustness of the electrical methodology to assess wheat root biomass and would be useful in pot studies and greenhouse/controlled conditions used in phenotyping. However, application to field trials requires the quantification of the impact of possible interfering factors. Our study was focused on a monocot crop grown in medium sized pots, measured during early growth stages with limited tillering and a moist soil. The electrical relations with root mass and our derived sensitivity score shall be tested with different species (particularly woody or non-woody species) and, more importantly, with contrasted soil water contents.

\section{Additional files}

Additional file 1: Table S1. Sensitivity score details and linear regression parameters between root dry mass and each electrical variable. The table lists the maximum determination frequency $\left(f_{\max } \mathrm{Hz}\right)$, sensitivity scores, maximum of coefficient of determination with root dry mass $\left(r_{n \text { nax }}^{2}\right)$ $y$-intercept of the linear regression (in standard unit of the related electrical variable) and slope (in standard unit of the related electrical variable per $\mathrm{g}$ ) for parallel capacitance $\left(\mathrm{C}_{\mathrm{p}}\right)$, serial capacitance $\left(\mathrm{C}_{\mathrm{s}}\right)$, parallel resistance $\left(R_{p}\right)$, serial resistance $\left(R_{s}\right)$, conductance magnitude $(G)$, impedance magnitude $(Z)$, reactance $(X)$ and impedance phase angle $(\theta)$ in 2T, 3T and 4T configurations, on average for 3 soil types.

Additional file 2: Figure S1. Coefficient of determination $\left(r^{2}\right)$ between root dry mass and parallel capacitance, in 2T configuration. The semi-log plot of the determination coefficients $\left(r^{2}\right)$ was obtained over a frequency range of 0.5 to $20,000 \mathrm{~Hz}$ (log scale), for plants grown in silt loam (+), loam $(\mathrm{x})$, sandy loam $(\mathbf{\Lambda})$, averaged for the three soil types (black dots).

Additional file 3: Figure S2. Coefficient of determination $\left(r^{2}\right)$ between root dry mass and parallel capacitance, in 4T configuration. The semi-log plot of the determination coefficients $\left(r^{2}\right)$ was obtained over a frequency range of 0.5 to $20,000 \mathrm{~Hz}$ (log scale), for plants grown in silt loam (+), loam $(\mathrm{x})$, sandy loam $(\mathbf{\Lambda})$, averaged for the three soil types (black dots).

Additional file 4: Figure S3. Illustration of a linear regression with high coefficient of determination and high sensitivity score $s$. Parallel capacitance measured at $116 \mathrm{~Hz}$, rated as the best configuration obtained in this study. Data from plants grown in pots containing loam, measured in 3T configuration.

Additional file 5: Figure S4. Illustration of a linear regression with high coefficient of determination but low sensitivity score $s$. Due to its high $r^{2}$, reactance measured at $20 \mathrm{kHz}$ may turn out to be a good candidate, however its interception is largely greater than zero implying a lowered score. Data from plants grown in pots containing loam, measured in $3 \mathrm{~T}$ configuration.

Additional file 6: Figure S5. Illustration of a linear regression with low coefficient of determination and low sensitivity score $s$. Low $r^{2}$ coupled with non-negligible intercept. Data from plants grown in pots containing sandy loam, measured in 3T configuration.

\section{Authors' contributions}

FP preformed the experiments. FP and CD jointly conceptualized the study, analysed the data, and wrote the manuscript. Both authors read and approved the final manuscript.

\section{Author details}

${ }^{1}$ ARVALIS Institut du végétal, 75116 Paris, France. ${ }^{2}$ UMR EMMAH, INRA, UAPV, Domaine Saint-Paul, Site Agroparc, 84914 Avignon, France.

\section{Acknowledgements}

This work was supported by Grants from the FSOV (French fund for plant breeding number FSOV 2012) involving INRA and ARVALIS Institut du végétal.

\section{Competing interests}

The authors declare that they have no competing interests.

Received: 2 March 2016 Accepted: 8 June 2016

Published online: 22 June 2016

\section{References}

1. FAO of the United Nations. Crop prospects and food situation. October (No. 3). Rome: FAO; 2014

2. Brisson N, Gate P, Gouache D, Charmet G, Oury F-X, Huard F. Why are wheat yields stagnating in Europe? A comprehensive data analysis for France. Field Crops Res. 2010;119:201-12.

3. Waines JG, Ehdaie B. Domestication and crop physiology: roots of greenrevolution wheat. Ann Bot. 2007;100:991-8.

4. Zhan A, Schneider H, Lynch JP. Reduced lateral root branching density improves drought tolerance in maize. Plant Physiol. 2015;168:1603-15.

5. Passioura JB. Grain yield, harvest index, and water use of wheat. J Aust Inst Agric Sci. 1977:43:117-20.

6. Manschadi AM, Christopher J, deVoil P, Hammer GL. The role of root architectural traits in adaptation of wheat to water-limited environments. Funct Plant Biol. 2006;33:823.

7. Manschadi AM, Hammer GL, Christopher JT, deVoil P. Genotypic variation in seedling root architectural traits and implications for drought adaptation in wheat (Triticum aestivum L.). Plant Soil. 2008;303:115-29.

8. Lilley JM, Kirkegaard JA. Benefits of increased soil exploration by wheat roots. Field Crops Res. 2011;122:118-30.

9. Ober ES, Werner P, Flatman E, Angus WJ, Jack P, Smith-Reeve L, et al. Genotypic differences in deep water extraction associated with drought tolerance in wheat. Funct Plant Biol. 2014;41:1078.

10. Bertholdsson N-O, Brantestam AK. A century of Nordic barley breeding-effects on early vigour root and shoot growth, straw length, harvest index and grain weight. Eur J Agron. 2009;30:266-74.

11. Araus JL, Cairns JE. Field high-throughput phenotyping: the new crop breeding frontier. Trends Plant Sci. 2014;19:52-61.

12. Comar A, Burger P, de Solan B, Baret F, Daumard F, Hanocq J-F. A semiautomatic system for high throughput phenotyping wheat cultivars in-field conditions: description and first results. Funct Plant Biol. 2012;39:914-24.

13. Trachsel S, Kaeppler SM, Brown KM, Lynch JP. Shovelomics: high throughput phenotyping of maize (Zea mays $L$.) root architecture in the field. Plant Soil. 2011;341:75-87.

14. Wasson AP, Richards RA, Chatrath R, Misra SC, Prasad SS, Rebetzke GJ, et al. Traits and selection strategies to improve root systems and water uptake in water-limited wheat crops. J Exp Bot. 2012;63:3485-98.

15. Polomski J, Kuhn N. Root research methods. In: Waisel Y, Eshel A, Kafkafi U, editors. Plant Roots Hidden Half. 3rd ed. Marcel Dekker NY Pub; 2002. pp $447-88$

16. Metzner R, Eggert A, van Dusschoten D, Pflugfelder D, Gerth S, Schurr U, et al. Direct comparison of MRI and X-ray CT technologies for 3D imaging of root systems in soil: potential and challenges for root trait quantification. Plant Methods. 2015;11:17.

17. Chloupek $O$. The relationship between electric capacitance and some other parameters of plant roots. Biol Plant. 1972;14:227-30.

18. Dalton FN. In-situ root extent measurements by electrical capacitance methods. Plant Soil. 1995;173:157-65.

19. Aulen M, Shipley B. Non-destructive estimation of root mass using electrical capacitance on ten herbaceous species. Plant Soil. 2012;355:41-9.

20. Cermak J, Radek U, Stranek Z, Koller J, Aubrecht L. Electrical measurement of tree root absorbing surfaces by the earth impedance method: 2 . Verification based on allometric relationships and root severing experiments. Tree Physiol. 2006;26:1113-21.

21. Cseresnyes I, Rajkai K, Vozary E. Role of phase angle measurement in electrical impedance spectroscopy. Int Agrophys. 2013;27:377-83. 
22. Ellis T, Murray W, Kavalieris L. Electrical capacitance of bean (Vicia faba) root systems was related to tissue density - a test for the Dalton Model. Plant Soil. 2013;366:575-84.

23. Ozier-Lafontaine $H$, Bajazet T. Analysis of root growth by impedance spectroscopy (EIS). Plant Soil. 2005;277:299-313.

24. van Beem J, Smith ME, Zobel RW. Estimating root mass in maize using a portable capacitance meter. Agron J. 1998;90:566-70.

25. Dietrich RC, Bengough AG, Jones HG, White PJ. Can root electrical capacitance be used to predict root mass in soil? Ann Bot. 2013;112:457-64.

26. Dietrich RC, Bengough AG, Jones HG, White PJ. A new physical interpretation of plant root capacitance. J Exp Bot. 2012;63:6149-59.

27. Nakhforoosh A, Grausgruber H, Kaul H-P, Bodner G. Wheat root diversity and root functional characterization. Plant Soil. 2014:380:211-29.

28. Heřmanská A, Středa T, Chloupek O. Improved wheat grain yield by a new method of root selection. Agron Sustain Dev. 2015;35:195-202.

29. Liao A, Zhou Q, Zhang Y. Application of $3 D$ electrical capacitance tomography in probing anomalous blocks in water. J Appl Geophys. 2015;117:91-103.

30. Samouëlian A, Cousin I, Tabbagh A, Bruand A, Richard G. Electrical resistiv ity survey in soil science: a review. Soil Tillage Res. 2005;83:173-93.

31. Nyce DS. Linear position sensors: theory and application. Hoboken: WileyInterscience; 2004.
32. Kendall WA, Pederson GA, Hill RR. Root size estimates of red clover and alfalfa based on electrical capacitance and root diameter measurements. Grass Forage Sci. 1982;37:253-6.

33. Zanetti C, Weller A, Vennetier M, Meriaux P. Detection of buried tree root samples by using geoelectrical measurements: a laboratory experiment. Plant Soil. 2011;339:273-83.

34. Cao Y, Repo T, Silvennoinen R, Lehto T, Pelkonen P. Analysis of the willow root system by electrical impedance spectroscopy. J Exp Bot. 2011;62:351-8

35. Chloupek O, Dostál V, Středa T, Psota V, Dvořáčková O. Drought tolerance of barley varieties in relation to their root system size. Plant Breed. 2010;129:630-6.

36. Ellis TW, Murray W, Paul K, Kavalieris L, Brophy J, Williams C, et al. Electrical capacitance as a rapid and non-invasive indicator of root length. Tree Physiol. 2013;33:3-17

37. Chloupek O. Evaluation of the size of a plant's root system using its electrical capacitance. Plant Soil. 1977;48:525-32

\section{Submit your next manuscript to BioMed Central and we will help you at every step:}

- We accept pre-submission inquiries

- Our selector tool helps you to find the most relevant journal

- We provide round the clock customer support

- Convenient online submission

- Thorough peer review

- Inclusion in PubMed and all major indexing services

- Maximum visibility for your research

Submit your manuscript at www biomedcentral com/submit
() Biomed Central 